\title{
Oral Argument and Impression Management: Harnessing the Power of Nonverbal Persuasion for a Judicial Audience
}

\author{
Michael J. Higdon ${ }^{*}$
}

I believe that I spent too much time in the last campaign on substance and too little on appearance....

—Richard Nixon, after losing the 1960 presidential election ${ }^{1}$

\section{INTRODUCTION}

This famous quote was prompted by the somewhat startling revelation that occurred during the 1960 televised debate-the first presidential debate ever broadcast on television-between Nixon and John F. Kennedy. ${ }^{2}$ This revelation arose primarily from audience reactions to the debate. ${ }^{3}$ Specifically, the majority of those who listened to the debate on the radio believed Nixon was the victor or, at least, considered it a draw between the two candidates. ${ }^{4}$ The majority of those who watched the event, however, had a very different opinion. In fact, this latter group declared Kennedy to be the overwhelming winner. ${ }^{5}$

Part of the reason for the disparity of opinion between those who saw the debate and those who merely listened was Nixon's physical

\footnotetext{
*awyering Process Professor, William S. Boyd School of Law, University of Nevada, Las Vegas. Deans John White, Kay Kindred, and Ann McGinley provided financial support for this project, made possible in part by the generosity of William S. Boyd and James E. Rogers. I also thank my colleagues at the Boyd School of Law, especially Terrill Pollman, Peter Bayer, Chad Schatzle, and Rebecca Scharf. Finally, a special thank you to Ruth Anne Robbins for her invaluable encouragement and advice.

1. See Dan Nimmo, Political Persuaders: The Techniques of Modern Election CAMPAignS 184 (2001).

2. See id. at $183-84$.

3. See id. at 184 .

4. See Paul F. Boller, Jr., Presidential Campaigns 299 (1984) ("Radio listeners had the impression that Nixon did as well as, if not better than, Kennedy in the confrontation; but televiewers, including Nixon's own fans, generally agreed that Kennedy came out ahead in the first debate.").
}

5. Id. 
appearance. ${ }^{6}$ He wore a grey suit, which blended in with the background; he had a noticeable five o'clock shadow; and he was visibly sweating throughout much of the debate. ${ }^{7}$ Physical appearance, however, was only part of Nixon's problems. As one body language expert pointed out, Nixon also displayed questionable nonverbals:

Nixon sits with a tense, narrow posture, while Kennedy sits with legs crossed, hands resting easily, his weight centered. In the medium camera shots, Nixon can be seen gripping the lectern tightly and not gesticulating for long periods of time, although his head movements are clear and emphatic. And Nixon displays a disastrous pattern of hyperblinking - not just abnormally frequent (more than one per second), but at times with such rapid flutters that his eyes momentarily close... B By comparison Kennedy clearly wins despite his rather ordinary and constricted showing. ${ }^{8}$

I describe this event as a "startling revelation" because, at that time, television was still a recent phenomenon, and this televised debate made it clear to politicians that, when it comes to persuasion, visual presentation alone is an extremely powerful component. As a result, politicians have become much savvier in using not only their words, but other nonverbal means of communication to create favorable impressions among potential voters. In fact, so central today are the concepts of nonverbal communication to political science that it is relatively common to see the news media commenting on a political candidate's nonverbal skills. ${ }^{9}$

Although American politics was perhaps the first genre in which the power of body language presented itself to the masses, for some time prior, social scientists had already begun studying the persuasive impact of nonverbal communication. ${ }^{10}$ In fact, it is largely because of this research that today we are able to understand why exactly Nixon's nonverbal behavior during the 1960 debate was "bad." Indeed, since that

6. Mary Cassata \& Thomas Skill, Television: A Guide to the Literature 83 (1985) ("No one can deny, for instance, that in the televised 1960 presidential campaign debates, Nixon's haggard appearance, capped by a heavy growth of 'five o'clock shadow,' tipped the 1960 election scales in favor of the more alert, clean-cut Kennedy.").

7. See, e.g., Mark L. Knapp \& Judith A. Hall, Nonverbal Communication in Human InTERACTION 456 (6th ed. 2006); Martha Davis, Presidential Body Politics: Movement Analysis of Debates and Press Conferences, 106 SEMIOTICA 205, 213 (1995).

8. Davis, supra note 7, at 213.

9. See, e.g., Amy Argetsinger, Read Her Lips. And Hands. Oh, and Eyes, Too: At Debate, Nonverbal Cues May Speak Louder Than Words, WASH. POST, Sept. 28, 2007, at C1 (analyzing the body language of the leading Democratic contenders for President at that time, including Hillary Clinton and Barack Obama).

10. See, e.g., infra note 32 . 
debate, the study of nonverbal communication and its impact on persuasion has continued to grow, revealing a much deeper understanding on the power of the human body as a communicative tool. As a result, many people (and not just politicians) are now much more conscious of their own nonverbal cues and what exactly those cues are communicating to others. In fact, because of this increasing level of interest, as well as the greater availability of information on nonverbal communication, today there exist a number of "self-help" books to help average readers harness the power of their nonverbal communication to help achieve greater success in such areas as business, romantic relationships, and social situations in general. ${ }^{11}$

At the same time, social scientists continue to explore the power of nonverbal communication and its impact within a variety of different settings. Within the legal setting, for example, social scientists have studied the impact of nonverbal cues on jurors. ${ }^{12}$ And, indeed, some law review articles have even reported on these findings. ${ }^{13}$ What neither legal scholarship nor social science has examined, however, is how nonverbal persuasion operates within the context of oral argument, i.e., arguments directed not at a jury, but at a judge. In this latter situation, the dynamics of the presentation shift somewhat given that (1) the format, and thus the presentation style, is much more formal and constrained and (2) the judge holds a position of dominance over the attorney, which greatly influences the acceptable range of appropriate nonverbal cues from which the attorney can draw.

Accordingly, the purpose of this Article is to help fill that gap and provide guidance to attorneys on effective impression management techniques during oral argument. To do this, Part II will first discuss why attorneys should educate themselves on the principles of nonverbal persuasion. Next, Part III will explore what social science in general has revealed about those areas of nonverbal persuasion that are likely to arise during the typical oral argument. Finally, using that information, Part IV

11. See, e.g., Alan Axelrod, Getting Your Way Every Day: Mastering the Lost ART of Pure Persuasion (2007); David Lewis, The Secret Language of Success: Using Body Language to Get What You Want (1989); Tonya Reiman, The Power of Body Language: HOW TO SUCCEED IN EVERY BUSINESS AND SOCIAL ENCOUNTER (2007).

12. See, e.g., J. Kevin Barge et al., The Effects of Nonverbal Communication and Gender on Impression Formation in Opening Statements, 54 S. COMM. J. 330 (1989); Patricia Rockwell \& Amy Ebesu Hubbard, The Effect of Attorneys' Nonverbal Communication on Perceived Credibility, 2 J. CREDIBILITY ASSESSMENT \& WiTNESS PSYCHOL. 1 (1999).

13. See, e.g., D.A. Clay, Note, Race and Perception in the Courtroom: Nonverbal Behaviors and Attribution in the Criminal Justice System, 67 TUL. L. REV. 2335 (1993); Lance Stockwell \& David C. Schrader, Factors That Persuade Jurors, 27 U. ToL. L. REV. 99 (1995). 
will formulate suggestions and guidance to attorneys seeking to improve the effectiveness of their nonverbal skills when arguing before a judge.

\section{Why ATtORNEYS SHOUlD CONCERN THEMSELVES WITH NONVERBAL PERSUASION}

When attorneys prepare for oral argument, they typically focus on the substance of the arguments. Indeed, the leading textbooks on legal advocacy instruct attorneys that the keys to an effective oral argument are to create a persuasive theme for your case, select your strongest arguments, and, when making those arguments, carefully choose your words. ${ }^{14}$ Such advice is not misplaced. In fact, this Article agrees that all of those considerations are important, and any attorney would be well served to primarily concentrate on those areas when preparing for oral argument. Beyond that, however, an attorney would be wise to learn from the Nixon quote that began this Article and not focus exclusively on substance, but also spend time thinking about the form of the presentation.

In fact, many social scientists caution against analyzing verbal and nonverbal communication separately given that the two modes of communication actually complement each other in terms of the information they communicate to receivers. ${ }^{15}$ Specifically, social scientists have posited that, in instructional settings, verbal messages help promote cognitive meanings in receivers (i.e., the substance of the message), while nonverbal messages help promote affective meanings (i.e., the receiver's feelings and attitudes toward that message). ${ }^{16}$ Furthermore, given that affective meaning is a key component of persuasion, nonverbal communication vis-à-vis verbal communication becomes even more important. Indeed, as one of the leading texts on nonverbal communication points out, a strong verbal delivery will result

14. See, e.g., Mary Beth Beazley, A Practical Guide to Appellate Advocacy (2d ed. 2006); Michael R. Fontham et Al., Persuasive Written and Oral AdVOCACy IN TRIal and ApPellate Courts (2d ed. 2007); DAVID C. Frederick, THE ART OF ORAL AdVOCACy (2003).

15. See Joseph N. Cappella \& Richard L. Street, Jr., Introduction: A Functional Approach to the Structure of Communicative Behaviour, in SEQUENCE AND PATTERN IN COMMUNICATIVE BEHAVIOUR 1 (Richard L. Street, Jr. \& Joseph N. Cappella eds., 1985) (noting that "the stimuli of social interaction are organized into functional groups and should be studied within [those] groups"); see also Janet Beavin Bavelas \& Nicole Chovil, Nonverbal and Verbal Communication: Hand Gestures and Facial Displays as Part of Language Use in Face-to-Face Dialogue, in THE SAGE HANDBOOK OF NONVERBAL COMMUNICATION 97 (Valerie Manusov \& Miles L. Patterson eds., 2006) (discussing how face-to-face dialogue reveals the importance of nonverbal acts in moment-bymoment interaction).

16. See James C. McCroskey et al., Nonverbal Communication in Instructional Contexts, in THE SAGE HANDBOOK OF NONVERBAL COMMUNICATION, supra note 15, at 421, 424. 
in greater attitudinal change if coupled with strong nonverbals. ${ }^{17}$ Also, in an advocacy setting, strong nonverbals are beneficial even when the verbal message is somewhat weak. Specifically, studies have found that a strong nonverbal presentation can actually distract a receiver from weaker substance. ${ }^{18}$

Additionally, an understanding of nonverbal persuasion is particularly important given that receivers are prone to put more weight on information gleaned through a speaker's nonverbal cues. As one social scientist put it, "the nonverbal channels carry more information and are believed more than the verbal band."19 This is so because it is assumed that nonverbal cues are more spontaneous, harder to fake, and less likely to be manipulated. ${ }^{20}$ Furthermore, these strong impressions formed by a speaker's nonverbals extend not only to the speaker's message but to the speaker himself. In fact, a couple of social studies have found that receivers are prone to ascribe durable character traits to a stranger based simply on an initial and limited exposure to that stranger's nonverbal behavior. ${ }^{21}$

Finally, attorneys would be well served to learn more about nonverbal persuasion not only to better assess their existing presentation skills, but to actively improve those skills. Studies have shown that effective nonverbal communication, although perhaps more innate to some, can actually be taught and improved through training. ${ }^{22}$ Also, such training is not that difficult given that a large part of this education simply involves learning more about various nonverbal cues and their

17. Judee K. Burgoon et al., Nonverbal Communication: The Unspoken Dialogue 402 (1996) [hereinafter BURGOON ET AL., THE UNSPOKEN DiALOGUE].

18. See, e.g., Rashmi Adaval \& Robert S. Wyer, Jr., Communicating About a Social Interaction: Effects on Memory for Protagonists' Statements and Nonverbal Behaviors, $40 \mathrm{~J}$. EXPERIMENTAL SOC. PSYCHOL. 450 (2004) (finding that, when receivers were better able to recall a speaker's nonverbal actions, the recall of the actual message was weaker).

19. Judee K. Burgoon, Nonverbal Communication Research in the 1970s: An Overview, in 4 COMMUNICATION YEARBOOK 179, 184 (Dan Nimmo ed., 1980).

20. KNAPP \& HALL, supra note 7, at 14.

21. See, e.g., Robert Gifford, A Lens-Mapping Framework for Understanding the Encoding and Decoding of Interpersonal Dispositions in Nonverbal Behavior, 66 J. PERSONALITY \& SOC. PSYCHOL. 398 (1994) (studying the "cuetilization policies" of typical observers and hypothesizing that groups will agree on a person's disposition); Valerie Manusov \& J. Scott Rodriquez, Intentionality Behind Nonverbal Messages: A Perceiver's Perspective, 13 J. NONVERBAL BEHAV. 15 (1989) (examining the ways in which people decide if a nonverbal message was intentional).

22. See KNAPP \& HALL, supra note 7, at 66 ("In more rigorous studies using various media for nonverbal skill development, evidence does point to positive effects of training."); Ronald E. Riggio, Nonverbal Skills and Abilities, in THE SAGE HANDBOOK OF NONVERBAL COMMUNICATION, supra note 15 , at 80 ("Importantly, nonverbal skills, unlike personality traits, can be learned and improved."). 
impact on impression management. ${ }^{23}$ Accordingly, the remainder of this Article will explore those aspects of nonverbal communication that impact persuasion as a means of helping attorneys who wish to improve those skills as part of their advocacy arsenal.

\section{Nonverbal Persuasion: What Social Science ReVEals}

Although it has proved somewhat difficult to formulate a precise definition, "nonverbal communication" has generally been defined as "communication effected by means other than words." 24 Given this broad definition, it should come as little surprise that nonverbal communication is everywhere. Indeed, nonverbal communication pervades human interaction:

Every communicative act carries with it nonverbal components. In face-to-face conversations, in public addresses, and in televised or videotaped presentations, all the nonverbal channels come into play. Bodily actions such as gestures, facial expressions, posture, and eye contact; vocal behaviors such as pitch, loudness, and tempo; proximity and potential for touch; physical appearance cues such as attractiveness, dress, and grooming; time messages such as pacing and giving undivided attention; and surrounding furnishings and objects that may add to one's identity all play a part in creating the total communication. ${ }^{25}$

As this quote makes clear, there are many different ways in which one human being can communicate with another nonverbally. For that reason, social scientists have ultimately broken nonverbal communication down into seven basic codes of nonverbal behavior. These include (1) kinesics (i.e., what a speaker does with his body); (2) physical appearance (i.e., what a speaker looks like); (3) vocalics (i.e., what a speaker sounds like); (4) haptics (i.e., how a speaker physically touches an audience member); (5) proxemics (i.e., how a speaker uses physical space); (6) environment and artifacts (i.e., how a speaker uses instruments and his environment); and (7) chronemics (i.e., how a speaker manages his time). ${ }^{26}$

23. See, e.g., Mark Costanzo, Training Students to Decode Verbal and Nonverbal Cues: Effects on Confidence and Performance, 84 J. EDUC. PSYCHOL. 308 (1992) (investigating the effectiveness of using previous research as a means of teaching students how to interpret verbal and nonverbal behavior).

24. KNAPP \& HALL, supra note 7, at 5.

25. Burgoon ET AL., The UnSPoKen Dialogue, supra note 17, at 4.

26. Id. at $32,122-23$. 
In terms of persuasion, it is important to note that any and all of the above seven codes can influence a speaker's perceived persuasiveness. Nonetheless, because the focus of this Article is on oral argument, the remainder of this section will focus only on the first three codes because not only do they "have the greatest impact on visual and auditory senses, ${ }^{27}$ but all three are particularly germane to the strictures of oral argument. The next three codes will not be discussed given that lawyers engaging in oral argument would rarely touch a third party, would have little control over their physical space given that they are generally expected to remain behind a podium, ${ }^{28}$ and would have little opportunity to manipulate their environment or employ instruments (i.e., props) given the formality of oral argument. ${ }^{29}$ Finally, chronemics will be discussed only as part of the discussion on paralinguistics due to the fact that attorneys are generally given only a set amount of time for oral argument and, thus, the only degree to which the attorney can really manipulate time is through his rate of speaking. ${ }^{30}$

\section{A. Kinesics}

A man stands inside of a closed glass phone booth. You cannot hear a word he says, but you see his postures, gestures, and facial expressions. You see his kinesics. ${ }^{31}$

The term "kinesics" comes from the Greek word for movement (kinesis) and was introduced by anthropologist Ray Birdwhistell in $1952 .{ }^{32}$ It refers "to all aspects of 'body language'-movements of the head, face, eyes, limbs, and trunk - as a means of communication." ${ }^{33}$ In

27. Id.

28. See Margaret Z. JOHns, Professional Writing FOR LAWYers: SkiLls AND RESPONSIBILITIES 190 (1998) ("When arguing, stand at the podium facing the court. Moving around in the well of the courtroom is inappropriate.").

29. See Bradley G. Clary et Al., Advocacy on Appeal 114 (2001) ("During [oral] argument,.... [y]ou are not lecturing with the assistance of an overhead projector, Powerpoint presentation, or posterboard chart or picture; you are engaging the judges in a discussion of critical legal issues and public policy considerations.").

30. See infra notes 199-203 and accompanying text.

31. MARJORIE FINK VARGAS, LOUdER THAN WORDS: AN INTRODUCTION TO NONVERBAL COMMUNICATION 67 (1986).

32. See RAy L. Birdwhistell, Introduction to Kinesics: An ANNOtATion System For ANALYSIS OF BODY MOTION AND GESTURE 3 (1952) ("The term kinesics has been chosen to cover the multi-level approach (physical, physiological, psychological, and cultural) to" the phenomena of "body motion as related to the non-verbal aspects of inter-personal communication.").

33. Judee K. Burgoon et al., Nonverbal Influence, in THE PERSUASION HANDBOOK: Developments in TheOry AND Practice 445, 449 (James Price Dillard \& Michael Pfau eds., 2002) [hereinafter Burgoon et al., Nonverbal Influence]. 
the relatively short time since Birdwhistell coined the term, social scientists have found kinesics to be one of the single richest forms of communication. $^{34}$ Indeed, it has been estimated that a human can produce up to 700,000 different signals simply by manipulating his body. ${ }^{35}$ More specifically, Birdwhistell estimated a human face alone can produce 250,000 expressions to help it display up to 20,000 different emotions. ${ }^{36}$

Humans are not only extremely adept at delivering kinesic messages, but receiving them as well. As one leading text on nonverbal communication points out, "[o]bservers can distinguish movements as short as $1 / 50$ of a second." ${ }^{37}$ Social scientists explain this ability on the part of humans by pointing out that "[h]umans have a strong bias to attend to kinesic cues, as a result of the innate tendency to orient to others visually, the overtly noticeable and attention-getting characteristics of kinesics, and the many functions kinesic cues serve." 38

Not surprisingly, then, when focusing on persuasive communication, social scientists have revealed that kinesic cues are integral to a speaker's ability to influence a speaker. Indeed, as social scientists Bettinghaus and Cody point out, "there are a number of nonverbal behaviors that are consistently related to enhanced performance ratings in both public speaking and interview contexts." 39 Accordingly, any attorney who appears as an advocate before a judge needs to have at least a basic understanding of kinesics. Of course, an in-depth analysis of each and every kinesic cue that could possibly influence a receiver is certainly beyond the scope of this Article. Instead, this section will focus on those physical signals that are most likely to influence a receiver within the three main subcategories of kinesics: facial signals, body posture, and gestures.

\section{Facial Signals}

Although human beings use their entire bodies to communicate, the face is generally regarded as one of the biggest sources of nonverbal

\footnotetext{
34. See Burgoon et Al., The Unspoken Dialogue, supra note 17, at 33 (attributing this richness "in part to the large number of possible human body actions").

35. See id. (citing Mario Pei, The Story of Language (2d ed. 1965)).

36. Id. (citing RAY L. BiRdWhistell, Kinesics AND CONTEXT: ESSAYS ON BOdy Motion COMMUNICATION 8 (1970)).

37. Id.

38. Id. at 47 .

39. Erwin P. Betthinghaus \& Michael J. Cody, Persuasive Communication 124 (4th ed. 1987).
} 
communication. As Professors Knapp and Hall note, "[t]he face is rich in communicative potential. It is a primary site for communication of emotional states; it reflects interpersonal attitudes; it provides nonverbal feedback on the comments of others ...." 40 As a result, many social scientists classify the human face as the primary source of human communication, next to human speech. ${ }^{41}$ In fact, studies have revealed that receivers tend to pay more weight to a person's face than to other forms of nonverbal communication, a phenomenon known as "facial primacy." $" 42$

As an initial matter, it is important to note that a human's face will communicate information both by what it is doing (e.g., nodding or blinking) and, more simply, by the physical features it possesses (e.g., the distance between the eyes or the size of the nose). Thus, when discussing facial cues, social scientists differentiate between static features (appearance) and dynamic features (movement) of the face. ${ }^{43}$ Nonetheless, kinesis, the focus of this subsection, would only encompass the latter category of facial signals. Accordingly, the remainder of this subsection will instead focus on facial movements and, more specifically, on those facial movements social science has revealed to play a part in a speaker's ability to persuade.

\section{a. Eye Contact}

Eye contact is one of the chief ways in which a speaker can manipulate his face to persuade another. ${ }^{44}$ In fact, studies in a variety of different contexts have all revealed a strong correlation between eye contact and persuasion. $^{45}$ For example, studies have found that individuals who make eye contact with a receiver are more successful at

40. KNAPP \& HALL, supra note 7, at 295.

41. See id.

42. Id.

43. Alan J. FRIDlund \& JAmes A. Russell, The Functions of Facial Expressions: What's in a Face?, in The SAGE HANDBOOK OF NONVERBAL COMMUNICATION, supra note 15, at 299, 301 ("Our faces are exquisitely complex, in both appearance and movement, and people use both to make inferences about us.").

44. Burgoon et Al., The Unspoken Dialogue, supra note 17, at 383 (discussing the impact of nonverbal behavior on social influence and persuasion, and noting that "[a]mong kinesic cues, one of the most potent is eye contact or gaze").

45. See, e.g., Steven A. Beebe, Effects of Eye Contact, Posture and Vocal Inflection upon Credibility and Comprehension, 7-8 Australian SCAN: J. HuM. COMM. 57, 57-58 (1980) (noting studies suggest direct eye contact "may enhance a speaker's perceived credibility"); Michael B. LaCrosse, Nonverbal Behavior and Perceived Counselor Attractiveness and Persuasiveness, $22 \mathrm{~J}$. COUNSEling PSYCHOL. 563, 563 (1975) ("In studies of affiliative and persuasive behavior, the nonverbal categories found to be important [include] . . . eye contact . . ..."). 
soliciting charitable donations, ${ }^{46}$ getting passersby to accept pamphlets, ${ }^{47}$ and even getting a ride while hitchhiking. ${ }^{48}$ Likewise, studies of juror behavior have revealed similar results. For example, in a study of juror perceptions of witnesses, jurors consistently rated witnesses who averted gaze as less credible. ${ }^{49}$

In looking at why gaze enhances a speaker's ability to persuade, Professors Burgoon, Dunbar, and Segrin point out that increased eye contact contributes to two different methods of nonverbal persuasion: attraction and dominance. ${ }^{50}$ First, in terms of attraction, social scientists note that people are more predisposed to respond favorably to speakers whom they find attractive, and "[a]mong the most powerful indicators of attraction are eye contact and mutual gaze." ${ }^{.51}$ For example, a number of studies have shown that, in an interview setting, interviewees will rate an interviewer as more attractive when that interviewer employs more eye contact. $^{52}$

Second, looking at dominance, social scientists have shown that dominant individuals are seen as more credible than submissive individuals. ${ }^{53}$ Furthermore, eye contact is one of the ways in which humans communicate dominance. As one social scientist describes, "[e]ye contact is a complex way to communicate dominance.... while

46. See, e.g., Ray Bull \& Elizabeth Gibson-Robinson, The Influences of Eye-Gaze, Style of Dress, and Locality on the Amounts of Money Donated to a Charity, 34 HuM. REL. 895, 903 (1981).

47. Chris L. Kleinke \& David A. Singer, Influence of Gaze on Compliance with Demanding and Conciliatory Requests in a Field Setting, 5 Personality \& Soc. Psychol. Bull. 386, 388 (1979).

48. Mark Snyder et al., Staring and Compliance: A Field Experiment on Hitchhiking, 4 J. APPLIED SOC. PSYCHOL. 165, 168 (1974).

49. See Gordon D. Hemsley \& Anthony N. Doob, The Effect of Looking Behavior on Perceptions of a Communicator's Credibility, 8 J. APPLIED Soc. PsyCHOL. 136, 136 (1978) ("The results indicated that witnesses who averted their gaze were perceived to be less credible and, ultimately, the defendant for whom they testified was judged as more likely to be guilty.").

50. Burgoon et al., Nonverbal Influence, supra note 33, at 445.

51. Id. at 449

52. See, e.g., Mark Cook \& Jacqueline M.C. Smith, The Role of Gaze in Impression Formation, 14 BRit. J. SOC. \& CliniCAL Psychol. 19, 21-23 (1975) ("[A]mount of gaze does affect the impression formed of the person looking."); LaCrosse, supra note 45, at 565 ("[S]ubjects would rate counselors who manifested affiliative nonverbal behavior as significantly more attractive and persuasive than counselors who did not manifest these behaviors.").

53. See generally Judee K. Burgoon \& Norah E. Dunbar, Nonverbal Expressions of Dominance and Power in Human Relationships, in THE SAGE HANDBOOK OF NONVERBAL COMMUNICATION, supra note 15, at 279-82 ("Specifically, dominance is said to occur when one individual's assertive actions elicit complementary acquiescence by another."). It is important, however, to understand what social scientists mean by dominance. Specifically, "dominance" does not mean "domineeringness," but is instead a concept intertwined with power and status. See id. at 281-82. The easiest way to understand the meaning of "dominance" in this context is simply to note what dominance is not, and that is submissiveness. Id. Thus, a person conveys dominance when his nonverbals send the message that, within society at large, he is not a submissive individual. Id. 
averting gaze is likely to communicate submission." 54 Additionally, dominant individuals typically display a more relaxed demeanor, which is relevant to eye contact given that the absence of gaze is associated with social anxiety. ${ }^{55}$

Of course, it is important to note that all nonverbal cues have optimal levels of acceptance, and eye contact is a good example of that principle. Specifically, too much eye contact (i.e., staring) can actually undermine a speaker's ability to persuade. For example, in one study, an actor dropped a huge stack of papers, seemingly by accident, to see if someone would stop and assist her. ${ }^{56}$ The study revealed that fewer individuals were willing to assist when the actor stared at them. ${ }^{57}$ Part of the explanation for these results comes from studies that reveal the tendency of human receivers to interpret prolonged eye contact as threatening. ${ }^{58}$ Humans generally react to such a threat by fleeing. ${ }^{59}$ For example, in a study by Ellsworth et al., drivers who were stared at while stopped at a red light drove much more quickly through the intersection once the light turned green. ${ }^{60}$

Nonetheless, with that caveat about staring in mind, one of the primary ways nonverbal experts advise individuals to enhance their persuasiveness is by increasing eye contact with receivers. For example, Tonya Reiman notes the importance of "[u]sing eye contact often, if not always." 11 Indeed, Reiman advises: "If you have trouble maintaining eye contact, you must work on this critical skill. Studies have found that employers view prospective hires who don't make eye contact as unattractive, detached, passive, incompetent, and lacking composure and social skills." ${ }^{62}$ Likewise, to avoid the problems associated with staring,

54. Burgoon et al., Nonverbal Influence, supra note 33, at 455.

55. KNAPP \& HALL, supra note 7, at 353-54.

56. Burgoon ET AL., The Unspoken Dialogue, supra note 17, at 405.

57. Id.

58. See generally Phoebe Ellsworth \& J. Merrill Carlsmith, Eye Contact and Gaze Aversion in an Aggressive Encounter, 28 J. PERSONALITY \& SOC. PSYCHOL. 280 (1972) (In an experiment where subjects were allowed to deliver shocks to victims who looked aggressive, averted their gaze downward, or varied these behaviors randomly, subjects in the first two designs gave significantly more shocks to a victim who made eye contact than when he averted his gaze.).

59. BuRgOON ET AL., ThE UNSPOKEN DiAlogue, supra note 17, at 425 ("When situational or relational cues do not indicate an appropriate response, staring is more threatening, evokes more tension in the target, and increases the target's motivation to escape the situation.").

60. See Phoebe C. Ellsworth et al., The Stare as a Stimulus to Flight in Human Subjects: A Series of Field Experiments, 21 J. PERSONALITY \& SOC. PSYCHOL. 302, 302 (1972).

61. REIMAN, supra note 11 , at 53.

62. Id. As Reiman explains, "[w] hen you look another person in the eyes, you're saying that you feel good about yourself-you're confident, you're trustworthy, and you know what you're talking about." Id. at 51-52. 
David Lewis encourages readers to maintain eye contact "for between [sixty and seventy percent] of the time." ${ }^{\text {"3 }}$ According to Lewis, "[a]nything less is liable to be interpreted as a sign of shiftiness, unease[,] or a lack of confidence." 64

\section{b. Facial Expressivity \& Head Movements}

Aside from eye contact, other ways speakers can manipulate their face to persuade is by using expressions that project "more energetic and animated behavior." 65 Such behavior includes "variable facial expressions, ... head shaking and nodding,... [and] wide smiles." The reason for this is because, as social science has demonstrated, these kinds of facial expressions tend to increase a receiver's perception of the speaker's warmth and pleasantness, which in turn seem to facilitate influence. ${ }^{67}$ As Professor Caroline Keating describes:

Lack of expressivity tends to convey disinterest, aloofness, and coldness. When it comes to the nonverbal engine that powers selfpresentation, there seems to be no "neutral" gear, only "forward" and "reverse." Cues such as mutual gaze while smiling, nodding, and forward lean generally draw approach, whereas mouth and brow frowns, gaze avoidance or aggressive stares, tense body postures, and interpersonal space violations usually propel avoidance.

As the above quote demonstrates, when it comes to nonverbal persuasion, head nodding can be a very powerful tool. In fact, a 1994 study found that speakers who received high scores in the category of warmth and pleasantness nodded their heads often when interacting with a receiver. ${ }^{69}$ Furthermore, one study went so far as to examine the combined and separate impact of smiling, nodding, and eyebrow raising. ${ }^{70}$ Interestingly enough, the results revealed that the most powerful cue in terms of promoting a favorable impression was a smile,

\footnotetext{
63. LEWIS, supra note 11, at 140.

64. Id.

65. Burgoon \& Dunbar, supra note 53, at 288.

66. Id.

67. See Burgoon et AL., The UnSpoken Dialogue, supra note 17, at 408-09.

68. Caroline F. Keating, Why and How the Silent Self Speaks Volumes: Functional Approaches to Nonverbal Impression Management, in THE SAGE HANDBOOK OF NONVERBAL COMMUNICATION, supra note 15, at 323-24 (citations omitted).

69. Gifford, supra note 21, at 403 fig.5.

70. W. Gill Woodall et al., The Effects of Facial-Head Cue Combinations on Interpersonal Evaluations, 28 COMM. Q. 47, 47 (1980).
} 
followed by a head nod and then an eyebrow raise. ${ }^{71}$ Additionally, the study found that smiling and nodding, when combined, were the most effective two-cue combination. ${ }^{72}$

Finally, not only does head nodding play a role in nonverbal persuasion, but a number of studies have confirmed that head tilt also plays a subtle part in impression formation. ${ }^{73}$ For example, one study found that a head tilt can change a receiver's impression of someone from arrogant and unsociable to kind and thoughtful. ${ }^{74}$ Furthermore, in terms of persuasion, a 2007 study found that head tilting can increase a person's perceived trustworthiness, but, interestingly enough, only if tilted in a certain direction. ${ }^{75}$ Specifically, the study found that people who tilt their heads just eight degrees to the right of vertical were rated as more trustworthy than those who kept their heads upright or tilted to the left. $^{76}$

\section{Body Posture}

As noted earlier, the degree to which a person appears relaxed bears a positive relationship to that person's perceived dominance and status. ${ }^{77}$ As Professors Burgoon, Dunbar, and Segrin explain:

In mixed-status groups, individuals with higher rank typically exhibit postural relaxation (e.g., slumping in a chair, putting their feet up on [a] desk), but individuals with lower rank tend to show more postural restraint. This is probably due to the fact that, like soldiers standing at attention, low-status individuals must remain attentive and vigilant while the higher status individual is freer to relax and has less need to be watchful of others. ${ }^{78}$

\footnotetext{
71. Id. at $51-52$, tbl.2.

72. Id.

73. See, e.g., Emma Otta et al., The Effect of Smiling and of Head Tilting on Person Perception, 128 J. PSYCHOL. 323, 330-31 (1994) ("Head tilting [leads] to different evaluations by... perceivers ... on happiness, . . reliability, . . . and beauty.").

74. Eva Krumhuber et al., Temporal Aspects of Facial Displays in Person and Expression Perception: The Effects of Smile Dynamics, Head-tilt, and Gender, 31 J. Nonverbal BeHaV. 39, 42 (2007) (citing Hans-Peter Hirsbrunner et al., Movement in Human Interaction, in NONVERBAL BEHAVIOR AND COMMUNiCATION (Aron W. Siegman \& Stanley Feldstein eds., 2d ed. 1987)).

75. Id. at 48

76. Id. at 44,48

77. See supra note 55 and accompanying text.

78. Burgoon et al., Nonverbal Influence, supra note 33, at 455 (citations omitted).
} 
Given then that dominant individuals are perceived as more persuasive, ${ }^{79}$ an overly stiff posture can make it more difficult for a speaker to influence a receiver. Indeed, "[p]ostural rigidity conveys lack of composure, whereas postural relaxation improves credibility and power impressions. $" 80$ Additionally, a tense posture is frequently associated with self-doubt ${ }^{81}$ and even anger. ${ }^{82}$ This is not to suggest, however, that one should slouch. Instead, as body language expert Tonya Reiman advises, "[w]hether sitting or standing, maintain excellent posture.... Good posture shows the world you feel confident and secure." ${ }^{\prime 83}$ The point is merely that a person who is seeking to persuade another should avoid a posture that is overly rigid.

With these principles in mind, one of the specific ways a speaker can relax his posture in an attempt to persuade is by leaning forward just slightly. In fact, studies show that leaning forward is an affiliative cue associated with greater persuasiveness. ${ }^{84}$ Furthermore, in his seminal study on the relationship between posture and nonverbal communication, Professor William James found that a forward lean connotes a relatively positive attitude, while a backward lean connotes a more negative attitude. ${ }^{85}$ Specifically, James found that a backward-leaning and even an erect posture can lead to impressions of pride, conceit, arrogance, and disdain. ${ }^{86}$ Conversely, a forward-leaning posture has been linked to perceptions of higher involvement with, and a greater liking of, the task at hand. ${ }^{87}$

\section{Gestures}

Many speakers mistakenly assume that gesturing ${ }^{88}$ while speaking, at least during a formal presentation, is a bad habit that can only have one

79. See supra note 53 and accompanying text.

80. BurgOON ET AL., THE UNSPOKEN DiAlOGUE, supra note 17, at 383.

81. See, e.g., id. at 401 (discussing Catha Maslow et al., Persuasiveness of Confidence Expressed via Language and Body Language, 10 BRIT. J. SOC. \& CLINICAL PSYCHOL. 234, 238 (1971)).

82. See KNAPP \& HALL, supra note 7 , at 9.

83. REIMAN, supra note 11, at 231-32.

84. See, e.g., LaCrosse, supra note 45.

85. William T. James, A Study of the Expression of Bodily Posture, 7 J. GEN. PSYCHOL. 405, 409-17 (1932).

86. Id. at 432 .

87. KNAPP \& HALL, supra note 7 , at 9.

88. The term "gestures" refers to "movements made by the body or some part of it." Id. at 225. However, in discussing nonverbal communication, the term generally refers to movements of the hands and arms. Id. 
consequence: to undermine the effectiveness of the speaker's delivery. I say "mistakenly" because, as social science has shown, gesturing is not only a necessary component of effective communication but, when done properly, can greatly increase the speaker's persuasive impact.

As an initial matter, research has shown that, without gestures, a person's ability to communicate is greatly compromised. ${ }^{89}$ Specifically, a 1931 study asked participants to talk while eliminating "all gestures of the head, hands, face, and body." 90 Interestingly, the report found that none of the subjects were even able to carry out the exercise as instructed. ${ }^{91}$ Furthermore, " the speech ... lost its intonation, stress[,] and expressiveness; even the very selection of words needed for the expression of content became labored; there was a jerkiness to the speech, and a reduction of the number of words used." 92 Such difficulty is not that surprising when one considers the various roles that gestures perform in human communication. Indeed, gestures "may replace speech..., regulate the flow and rhythm of interaction, maintain attention, add emphasis and/or clarity to speech, help characterize and make memorable the content of speech, act as forecasters of forthcoming speech, and help speakers access and formulate speech." 93

Apart from being a necessary component to overall effective communication, gestures also play an integral role in communication that is specifically designed to persuade. Indeed, just as a more expressive face, as discussed earlier, ${ }^{94}$ is more frequently associated with greater persuasiveness, so too is a more expressive body, through the use of gestures. For example, several studies of job applicants have found that, "[a]s with other affiliative cues, more smiling, nodding, and gesturing are associated with greater persuasiveness and with greater success as a job applicant." $" 95$ Also, a study of counselors found that those who smiled, made eye contact, and gestured more were rated as being more persuasive. $^{96}$

89. See $i d$. at 243 (noting that gestures improve speaker fluency, facilitate listener comprehension, and allow a speaker to demonstrate spatial relationships).

90. Id. (citing S.M. Dobrogaev, The Study of Reflex in Problems of Linguistics, in 2 LAZYKOVEDENIE I MATERIALIZM 105 (E.A. Marr ed., 1931)).

91. Id.

92. Id. Indeed, other studies have confirmed the communication difficulties that speakers face when they are unable to gesture. See, e.g., Bernard Rimé \& Loris Schiaratura, Gesture and Speech, in Fundamentals of Nonverbal Behavior 239-81 (Robert S. Feldman \& Bernard Rimé eds., 1991).

93. KNAPP \& HALL, supra note 7, at 225-26.

94. See supra notes $65-68$ and accompanying text.

95. BuRGOON ET AL., THE UnSPOKEN DiALOGUe, supra note 17, at 408 (citation omitted).

96. See LaCrosse, supra note 45 , at 565 . 
This is not to suggest, however, that all gestures lead to an increased perception of persuasiveness. In fact, it is only those gestures that are "synchronized with and support[ive of] the vocal/verbal stream." "97 Indeed, when such synchronization is absent, studies have revealed a corresponding reduction in listener comprehension. ${ }^{98}$ Furthermore, gestures that are not in sync with a speaker's verbal message can very easily be seen as nervous gestures, which cause a speaker to appear less relaxed. ${ }^{99}$ As noted earlier, appearing relaxed is important to a speaker seeking to persuade a receiver. ${ }^{100}$ Thus, fidgeting gestures tend to undermine a speaker's effectiveness and, accordingly, are to be avoided.

A study of the 1976 presidential debate between Gerald Ford and Jimmy Carter illustrates this principle. In that study, participants watched portions of a debate between the two presidential candidates and were then asked to assign a favorability rating to those segments. ${ }^{101}$ Interestingly enough, the segments that the participants rated higher were those in which the candidates exhibited less nervous, tension-release gestures like lip-licking, postural sway, shifting gaze, and blinking. ${ }^{102}$ Additionally, the participants identified Ford, the candidate who exhibited the least number of these nervous gestures, as the winner of the debate. ${ }^{103}$ Aside from this study, some other nervous gestures that scientists have identified include: clicking pen caps, tapping one's foot, chewing on lips, pacing, picking at fingernails or lips, and finger drumming or tapping. ${ }^{104}$ In sum, fidgety gestures are harmful because they undermine the perceived dominance of the speaker and, as noted earlier, dominance is closely linked to perceived persuasiveness. ${ }^{105}$

97. KNAPP \& HALL, supra note 7, at 243.

98. Id. at 15 ("When the verbal and nonverbal channels are complementary, rather than conflicting, our messages are usually decoded more accurately."); see also Dale G. Leathers, The Impact of Multichannel Message Inconsistency on Verbal and Nonverbal Decoding Behaviors, 46 COMM. MONOGRAPHS 88, 98 (1979) (discussing behaviors, including "confusion, uncertainty, displeasure, hostility, and withdrawal," that receivers used to respond to inconsistent verbal and nonverbal messages).

99. See generally Peter H. Waxer, Nonverbal Cues for Anxiety: An Examination of Emotional Leakage, 86 J. ABNORMAL PSYCHOL. 306 (1977) (discussing how "nonverbal behavior 'might function as a leakage channel of communication less susceptible to either conscious deception or unconscious masking"').

100. See supra note 55 and accompanying text

101. See Ralph V. Exline, Multichannel Transmission of Nonverbal Behavior and the Perception of Powerful Men: The Presidential Debates of 1976, in POWER, DOMINANCE, AND NONVERBAL BEHAVIOR 183, 187-88 (Steven L. Ellyson \& John F. Dovidio eds., 1985).

102. Id. at 190-91.

103. Id. at 191 .

104. REIMAN, supra note 11 , at 131.

105. See supra note 53 and accompanying text. 
In fact, it is those gestures that connote dominance that researchers consistently identify as helpful to the public speaker seeking to persuade others. As one leading text on the subject of nonverbal persuasion notes: "Various gestures have been associated with power, dominance, and status.... Some evidence suggests that pointing at another person, using expressive and expansive gestures, steepling the hands, and using gestures while directing others may be dominant gestures."106 Specifically, "steepling," which refers to "the gesture of leaning the tips of the outstretched fingers of both hands against each other, creating an image reminiscent of a church steeple," 107 is widely considered a symbol of confidence and has frequently been employed by a number of political figures like Mikhail Gorbachev and Oliver North. ${ }^{108}$ As Susan Bixler states, "[t]he simple act of placing the fingertips of either hand together in front of you to form a steeple is a very effective gesture that is rarely offensive and will establish you as someone [who is] both evaluative and in control." 109

Additionally, researchers have found that hand gestures involving a palms-down orientation are particularly effective at communicating dominance, which again enhances a speaker's ability to persuade. As Professors Knapp and Hall note, palms-down typically communicates certainty while palms-up communicates uncertainty. ${ }^{110}$ Conversely, Tonya Reiman notes that "palms-down [is used] when someone wants to assert their authority or demonstrate a level of control over a situation." "111 Furthermore, Reiman characterizes the palms-up gesture as "a universal sign for supplication," noting that "[p]rimatologists have found this sign among chimpanzees who use it to beg for food ...."112 For this reason, some experts in the field of nonverbal communication advise speakers to use palms-down gestures when seeking to establish authority, such as in a presentation, ${ }^{113}$ or even when running for an elected office. ${ }^{114}$

\footnotetext{
106. Burgoon et al., Nonverbal Influence, supra note 33, at 455 (citations omitted).

107. M.D. Blum, The Silent SPEEch of POliticians: Body LANGUAGe In Government 3-13 (1988).

108. Id. at 3-14 to -16 .

109. Susan Bixler, The Professional Image: The Total Program for Marketing YOURSELF VISUALLY - BY AMERICA'S TOP CORPORATE IMAGE CONSULTANT 238 (1984).

110. KNAPP \& HALL, supra note 7, at 237; see also BURGOON ET AL., THE UNSPOKEN DiALOGUE, supra note 17, at 234 ("Palms-up gestures frequently accompany the shrug emblem, signifying uncertainty or hesitancy." (citation omitted)).

111. REIMAN, supra note 11, at 118.

112. Id. at 117 .

113. Id. at 119 .

114. See BLUM, supra note 107 , at 7-1 to -3 .
} 
Finally, it is important to note that expansive gestures are typically viewed as more persuasive than tightly constrained gestures. ${ }^{115}$ One of the reasons behind this result lies, once again, with dominance, but also with the nonverbal code of proxemics - a speaker's use of physical space. Specifically, dominant individuals simply take up more space. ${ }^{116}$ As one leading text on nonverbal communication points out, "[t]erritory is a key resource: people display status, dominance, and power by owning, controlling, and accessing more, and qualitatively better, territory." 117 This "territory" also includes personal space. In fact, social science research demonstrates that individuals of higher status tend to take up more personal space than those of lower status. ${ }^{118}$ Being expansive in their gestures is but one way speakers can seek to occupy greater personal space.

\section{B. Paralanguage}

Now imagine that you are on the other end of this telephone line. You cannot see any nonverbal communication, but you can hear more than his words. You can hear his paralanguage.

Paralanguage, also referred to as vocalics, refers quite simply to the vocal qualities and sounds associated with nonverbal communication. ${ }^{120}$ Like proxemics, paralanguage is a powerful tool in any human's communication arsenal. As Professors Burgoon, Buller, and Wood explain:

The voice is a rich channel in the nonverbal communication system. It contains many behaviors besides the spoken word that are used to complement, accent, emphasize, and contradict what is said, as well as to send additional messages. Pitch, loudness, silences, pauses, laughs, sighs, coughs, and sneezes are a few examples of cues in the code. ${ }^{12 \mathrm{~T}}$

\footnotetext{
115. See Burgoon et al., The Unspoken Dialogue, supra note 17, at 315 ("Conversely, submissive individuals tend to be more circumspect and 'tighter' in their behavior. They appear to 'shrink in,' using closed, symmetrical postures and small gestures or gestures that convey vulnerability ....").

116. See Burgoon et al., Nonverbal Influence, supra note 33, at 455 ("Higher status individuals are afforded more personal space, control access to more desirable territory, and adopt body positions that occupy more space as compared to lower status individuals." (citation omitted)).

117. Burgoon et AL., The UnSPoKen Dialogue, supra note 17, at 306 (citations omitted).

118. Burgoon et al., Nonverbal Influence, supra note 33, at 455; see supra note 116.

119. VARGAS, supra note 31, at 67.

120. KNAPP \& HALL, supra note 7, at 372.

121. Burgoon et Al., The UnSpoken Dialogue, supra note 17, at 58.
} 
Indeed, much of what we communicate as humans is not a product of what we say, but how we say it. For example, humans signal a declarative sentence by lowering pitch at the end of the sentence, while indicating a question by raising pitch. Furthermore, a human speaker can completely alter the meaning of a sentence simply by stressing one word over another. ${ }^{122}$ Finally, we can demonstrate heightened emotion simply by raising the volume of our voice. These are three examples of how we can consciously change our message simply by changing our voice.

Aside from altering meaning, in studying the power of paralanguage, social scientists have also found that the way in which one speaks can influence his ability to persuade another. Specifically, social scientists have identified the following list of variables that are frequently associated with greater perceived persuasiveness: faster speech, nonhesitant speech, more pitch variation, and loudness. ${ }^{123}$ As the remainder of this section will demonstrate, each of those variables, both individually and collectively, can greatly impact a speaker's ability to persuade.

\section{Faster Speech}

Of all these variables, the one that has perhaps received the greatest amount of attention from social scientists, as a contributor to persuasiveness, is a speaker's rate of speaking. For example, one study found that those who speak at a relatively faster rate are viewed more favorably than those who speak at a relatively slower rate. ${ }^{124}$ Indeed, a number of studies have confirmed that a faster speaking tempo enhances perceptions of a speaker's competence, status, dominance, intelligence,

\footnotetext{
122. Consider the following example:

1. He's giving this money to Herbie. ( $\mathrm{He}$ is the one giving the money, nobody else.)

2. He's giving this money to Herbie. (He is giving, not lending, the money.)

3. He's giving this money to Herbie. (The money being exchanged is not from another fund or source; it is this money.)

4. He's giving this money to Herbie. (Money is the unit of exchange, not flowers or beads.)

5. He's giving this money to Herbie. (The recipient is Herbie, not Eric or Bill or Rod.) KNAPP \& HALL, supra note 7, at 370.

123. See Judee K. Burgoon et al., Nonverbal Behaviors, Persuasion, and Credibility, 17 Hum. COMM. RES. 140, 152 (1990). Additionally, a landmark 1969 study identified four vocal cues that, when present, enhance the perceived persuasiveness of the speaker: louder amplitude, greater intonation, more fluency, and faster tempo. See Albert Mehrabian \& Martin Williams, Nonverbal Concomitants of Perceived and Intended Persuasiveness, 13 J. Personality \& Soc. Psychol. 37, 54, 56 (1969).

124. See Aron W. Siegman, The Telltale Voice: Nonverbal Messages of Verbal Communication, in NONVERBAL BeHAVIOR AND COMmunication 351, 371 (Aron W. Siegman \& Stanley Feldstein eds., 2d ed. 1987).
} 
objectivity, and even overall knowledge. ${ }^{125}$ Interestingly, one of the possible explanations behind this perception lies in the area of chronemics, or "how humans perceive, structure, and use time as communication." "26 Researchers have found that time management can be a powerful status cue and thus may explain the positive perception of those who speak more quickly and, thus, make more efficient use of their time. $^{127}$

In fact, in terms of trying to persuade, studies indicate that the only instance in which a slower speaking rate is advisable is if the slower rate will be perceived by the receiver as helpful. ${ }^{128}$ For instance, a reduced rate will likely be more palatable if it appears intended to help a receiver understand a difficult or unfamiliar topic. ${ }^{129}$

Of course, the rate of speaking, like the other three vocalic cues discussed here, does have limits to its effectiveness. As Professors Knapp and Hall note, "[t]here are probably upper limits to the effective range on each of these variables, so that extremes would produce less, not more, credibility or persuasion." 130 In terms of the rate of speech, one study found that, although a faster tempo was viewed as more persuasive, there is an upper limit (around 375 syllables per minute), after which judgments concerning persuasiveness can level off or even decrease. $^{131}$

\section{Nonhesitant Speech}

Just as a faster tempo can enhance perceived persuasiveness, a slower, more hesitant, tempo can undermine that perception. For example, one study of trial transcripts compared what researchers labeled as "powerful" versus "powerless" speech. ${ }^{132}$ The latter was defined as the style of speech generally associated with those lower in status (defendants and lay witnesses) and included a high frequency of hedges (e.g., "kind of"), hesitations (e.g., "um"), intensifiers (e.g., "clearly"),

\footnotetext{
125. BURgOON ET AL., THE UNSPOKEN Dialogue, supra note 17, at 380 .

126. Id. at 122 .

127. See, e.g., Burgoon et al., Nonverbal Influence, supra note 33, at 457 ("Perhaps it is their attempt to maximize the use of their own time or our perception that people in a hurry are important that leads us to associate these people with credibility.").

128. BURGOON ET AL., THE UNSPOKEN DiAlOgUe, supra note 17, at 381.

129. Id.

130. KNAPP \& HALL, supra note 7, at 390.

131. BURGOON ET AL., THE UNSPOKEN DiAlogue, supra note 17, at 400.

132. Bonnie Erickson et al., Speech Style and Impression Formation in a Court Setting: The Effects of "Powerful" and "Powerless" Speech, 14 J. EXPERIMENTAL SOC. PsychOL. 266, 266
} (1978). 
and polite forms (e.g., "please"; "sir"). In contrast, those of high status (lawyers, judges, and expert witnesses) employed "powerful" speech, which contained a relatively small number of these elements. ${ }^{133}$ Subsequently, the researchers conducted a survey, which found that participants rated this "powerful" speaking style as more credible, sociable, and even attractive. ${ }^{134}$ Likewise, another study found that speech containing a higher percentage of pauses and hesitations undermines the perceived attractiveness of the speaker. ${ }^{135}$ As noted earlier, perceptions of attractiveness are positively correlated with perceived persuasiveness. ${ }^{136}$

\section{More Pitch Variation}

Unfortunately, studies that have looked at the impact of pitch level on perceptions of credibility are inconsistent in their findings. Some of these studies have found that higher pitch fosters impressions of competence and dominance. ${ }^{137}$ Other studies, however, indicate that higher pitch is more associated with negative impressions, and that deeper pitch is preferred. ${ }^{138}$ In an attempt to explain this seeming contradiction, some social scientists have noted that " $[\mathrm{t}]$ he conflicting findings may be due partly to different acceptable pitch ranges for male and female voices. Increases in male pitch may result in positive impressions; but at the point at which a man starts to sound like a woman, impressions may suffer."139 Nonetheless, when it comes to pitch, studies are consistent on one point. Namely, greater variation in pitch enhances credibility. ${ }^{140}$

133. Id. at 267. Others have described the two speaking styles as "confident" and "doubtful." See Maslow et al., supra note 81, at 234.

134. Erickson et al., supra note 132, at 268. In addition, other studies indicate that "voices regarded as higher status, dominant, and confident display (1) lower pitch, (2) greater loudness, (3) moderately fast tempo, (4) clearer articulation and enunciation, (5) more intonation, and (6) no accent." BURGOON ET AL., THE UNSPOKEN DiAlogUe, supra note 17, at 316 (citations omitted).

135. Burgoon et al., Nonverbal Influence, supra note 33, at 449 (discussing Aron Wolfe Siegman \& Benjamin Pope, Ambiguity and Verbal Fluency in the TAT, 30 J. CONSULTING PSYCHOL. 239, 239 (1966)).

136. See supra notes 50-52 and accompanying text.

137. See, e.g., Klaus R. Scherer, Personality Inference From Voice Quality: The Loud Voice of Extroversion, 8 EUR. J. SOC. PSYCHOL. 467, 472-77 (1978) (detailing a study of speakers' voices).

138. See, e.g., William Apple et al., Effects of Pitch and Speech Rate on Personal Attributions, 37 J. PERSONALITY \& SOC. PSYCHOL. 715, 720 (1979) (noting that "judges rated high-pitched voices as less truthful than lower pitched voices").

139. BURGOON ET AL., THE UnSPOKEN Dialogue, supra note 17, at 381.

140. See, e.g., David W. Addington, The Effect of Vocal Variations on Ratings of Source Credibility, 38 SPEECH MONOGRAPHS 242, 246 (1971) (finding that "decreases in [pitch] variety were related to substantially lower credibility ratings"); George B. Ray, Vocally Cued Personality 


\section{Loudness}

In addition, social science research has revealed that increasing the volume of one's voice, up to a moderately high level, increases the perceived credibility of a speaker. Specifically, studies have found that a louder voice communicates a number of positive attributes including dominance, competence, and even emotional stability. ${ }^{141}$

Although each of the four paralinguistic cues discussed here can influence perceived credibility and persuasiveness, the greatest impact comes when all are incorporated into a speaker's presentation. As one scholar put it, "the advice for someone who wants to appear poised, competent, and powerful is to speak rapidly, fluently[,] and loudly with few pauses [and] with deep and varied pitch." 142 Indeed, a study of jury behavior found that jurors "who were perceived as influential spoke with a more expressive voice, varying their intonation contours within a greater range, and with a somewhat louder voice."143

\section{Physical Appearance}

Through tattered rags small vices do appear: Robes and furred gowns hides all. ${ }^{144}$

As the preceding subsections demonstrate, a speaker can manipulate both his body and voice to increase his perceived credibility and persuasiveness. However, beyond these dynamic components of kinesics and paralinguistics, any discussion of nonverbal persuasion would be incomplete without taking into account the role that static physical appearance plays. Indeed, social scientists have suggested that physical appearance is perhaps the most influential aspect of nonverbal

Prototypes: An Implicit Personality Theory Approach, 53 COMM. MONOGRAPHS 266, 268, 273-74 (1986) (finding that increases in pitch variation "occurred with increased ratings of benevolence and/or social attractiveness").

141. See, e.g., Charles D. Aronovitch, The Voice of Personality: Stereotyped Judgments and Their Relation to Voice Quality and Sex of Speaker, 99 J. Soc. PsYchol. 207, 216-18 (1976) (noting that "loudness [is a] cue[] upon which judgments of a speaker's personality were found to be based"); Klaus R. Scherer, Voice and Speech Correlates of Perceived Social Influence in Simulated Juries, in LANGUAGE AND Social PSYChOlOGY 88, 104-05 (Howard Giles \& Robert N. St. Clair eds., 1979) (discussing how jurors who spoke with a more expressive voice were perceived as more influential, sociable, and likeable).

142. Burgoon ET AL., The Unspoken Dialogue, supra note 17, at 382.

143. Scherer, supra note 137, at 104-05.

144. William ShaKeSPEARE, King LeAR act 4, sc. 6, 11. 154-55. 
communication because it is the first cue one receives when first encountering a speaker. ${ }^{145}$

Regardless of how important physical appearance actually is vis-àvis the other components of nonverbal persuasion, studies have proven that being more attractive increases one's effectiveness as an advocate. For example, one study employed student canvassers who attempted to persuade passersby to sign a petition banning meat from lunch and dinner in the campus cafeteria. ${ }^{146}$ The study found that those canvassers who were independently judged as more attractive had greater success. ${ }^{147}$ A similar study found that both men and women who were judged to be more attractive were also judged to possess better sales skills, were treated more cordially and were able to produce more willingness on the part of others to contribute to a charitable organization. ${ }^{148}$ Furthermore, even studies of jury behavior have confirmed that jurors tend to favor attractive defendants. ${ }^{149}$

The question, then, that presents itself is: what do humans consider "attractive"? Well, many of the variables that help determine a person's general level of attractiveness are attributes that speakers have little to no control over. These qualities include a person's facial symmetry, ${ }^{150}$ height, ${ }^{151}$ skin color, ${ }^{152}$ and even body shape. ${ }^{153}$ Nonetheless, there are some characteristics over which speakers do have control, which they can manipulate to increase perceived attractiveness. Given that

145. See Rockwell \& Hubbard, supra note 12, at 2 .

146. Shelly Chaiken, Communicator Physical Attractiveness and Persuasion, $37 \mathrm{~J}$. PERSONALITY \& SOC. PSYCHOL. 1387, 1390 (1979).

147. Id. at $1394-95$.

148. Peter H. Reingen \& Jerome B. Kernan, Social Perception and Interpersonal Influence: Some Consequences of the Physical Attractiveness Stereotype in a Personal Selling Setting, 2 J. CONSUMER PSYCHOL. 25, 25 (1993).

149. See John C. Reinard, Persuasion in the Legal Setting, in The Persuasion Handbook: DEVELOPMENTS IN THEORY AND PRACTICE, supra note 33, at 543, 549.

150. See, e.g., Karl Grammer \& Randy Thornhill, Human (Homo sapiens) Facial Attractiveness and Sexual Selection: The Role of Symmetry and Averageness, 108 J. COMP. PSYCHOL. 233 (1994) (detailing a study, which concludes "that facial symmetry has a positive influence on facial attractiveness ratings").

151. See, e.g., Brian Stabler et al., Social Judgments by Children of Short Stature, 46 PSYCHOL. REP. 743, 743 (1980) ("There is a pervasive social attitude which associates tallness with positive psychological characteristics and assigns negative attributes to shortness.").

152. See, e.g., KNAPP \& HALL, supra note 7, at 195-96 (We make judgments "about temporary color changes that show up on peoples' bodies.... But in many respects, permanent skin colors have been the most potent body stimulus for determining interpersonal responses in our culture.").

153. See, e.g., William D. Wells \& Bertram Siegel, Stereotyped Somatotypes, 8 PSYCHOL. REP. 77,78 (1961) (analyzing the link between physique and personality); see also Richard M. Lerner \& Elizabeth Gellert, Body Build Identification, Preference, and Aversion in Children, 1 DEVELOPMENTAL PSYCHOL. 456, 460 (1969) (noting that even children prefer more muscular builds to thin or obese body types). 
"[a]nother strategy that may allow a communicator to exert influence is to maximize one's attractiveness," 154 it is important for oral advocates to have an understanding of these strategies.

First of all, much of the proxemic and paralinguistic suggestions discussed earlier ${ }^{155}$ have the dual benefit of increasing not just overall perceptions of persuasiveness but also, more specifically, perceptions of attractiveness. Indeed, it is partly because those cues increase a speaker's perceived attractiveness that they have the added benefit of enhancing credibility. ${ }^{156}$ For example, as mentioned earlier, eye contact can make a speaker appear more attractive to a receiver; ${ }^{157}$ the paralinguistic qualities discussed earlier that are deemed more persuasive can also increase perceptions of attractiveness. ${ }^{158}$

Moving beyond kinesic and paralanguage cues, hair style has also been shown to affect attractiveness and credibility. For example, in terms of men, some studies have found that men with shorter hair are rated as "more competent, dynamic, intelligent, masculine, mature, wise, and attractive than long-haired men." "159 Similarly, for women, another study found that women with short hair were perceived as more competent than those with long hair. ${ }^{160}$ Accordingly, body language experts typically advise women with long hair to wear their hair short or "up" when trying to create a more professional impression. One such expert advises women as follows: "Ladies, long hair, worn down, no matter how nicely it is kept, no matter how good it looks, is not usually considered professional." 16

Furthermore, social science has also shown that mode of dress can have quite a bit of influence on first impressions. As one scholar notes, "[c]lothing is part of [the] nonverbal arsenal of impression management techniques." 162 And what a potent weapon it is. In fact, one study found that, for both men and women, clothing was one of the first things people

\footnotetext{
154. Burgoon et AL., The Unspoken Dialogue, supra note 17, at 409.

155. See supra Parts III.A, III.B.

156. See supra notes 50-52 and accompanying text.

157. Id.; see also Burgoon et al., Nonverbal Influence, supra note 33, at 449 ("Eye contact is both encoded and decoded as a sign of attraction and relational positivity ...." (citations omitted)).

158. See Burgoon et al., Nonverbal Influence, supra note 33, at 449 (discussing the impact that speech rate and use of pauses/hesitations have on perceived attractiveness).

159. Burgoon Et AL., The Unspoken Dialogue, supra note 17, at 383.

160. See Shawn W. Rosenberg et al., Creating a Political Image: Shaping Appearance and Manipulating the Vote, 13 POL. BEHAV. 345, 352, tbl.1 (1991) (analyzing the success of female political candidates).

161. REIMAN, supra note 11, at 222.

162. Keating, supra note 68 , at 325.
} 
notice when meeting someone for the first time. ${ }^{163}$ Also, a person's clothing can have quite an impact on how that person is perceived. For example, studies have shown that wearing high-status clothing can increase a speaker's perceived attractiveness, credibility, intelligence and persuasiveness. ${ }^{164}$ Likewise, another study found that an individual's intelligence is rated higher when that person is dressed formally. ${ }^{165}$ Additionally, several studies have found that, in the classroom setting, teachers who dress informally are viewed as less intelligent and, thus, command only limited respect. ${ }^{166}$ The reason behind all these results is apparently that "[c]redibility and persuasion ability are associated with formal attire because high-status and privileged members of society tend to wear formal forms of dress more often than do low-status members. $" 167$

\section{HARNESSING THE POWER OF NONVERBAL PERSUASION TECHNIQUES DURING ORAL ARGUMENT}

In looking at the social science behind nonverbal persuasion discussed above, it becomes evident that attorneys would be wise to understand that their movements, voices, and physical appearance all have the potential to either enhance or to undermine the attorneys' ability to persuade. Accordingly, in light of the studies detailed in Part III, this section will explore ways in which attorneys can (and probably should) manipulate their bodies through kinesics and physical appearance, as well as their voices through paralinguistics, to become better oral advocates. Furthermore, against this backdrop, this section will also incorporate advice from some of the leading texts on oral argument to illustrate how studies of nonverbal communication better support and explain some of the more popular tips relating to oral advocacy.

Of course, in applying this social science, one must be mindful of the fact that the particular dynamics of a judicial audience require some caution. Specifically, in oral argument, unlike many other situations in

163. See KNAPP \& HALL, supra note 7, at 204 ("Females noticed clothes first for both same- and opposite-sexed partners; males also looked at clothes first for same-sexed partners, but for members of the opposite sex, clothes took third place behind figure and face.").

164. See Burgoon et al., Nonverbal Influence, supra note 33, at 451, 457.

165. See Dorothy U. Behling \& Elizabeth A. Williams, Influence of Dress on Perception of Intelligence and Expectations of Scholastic Achievement, 9 ClOTHING AND TEXTILES RES. J. 1, 4 (1991) ("For both male and female models intelligence was judged to be highest in the Dressy look ....").

166. See, e.g., Sara Butler \& Kathy Roesel, Research Note, The Influence of Dress on Students' Perceptions of Teacher Characteristics, 7 ClOTHING AND TEXTILES RES. J. 57, 58-59 (1989).

167. Burgoon et al., Nonverbal Influence, supra note 33, at 457. 
which a speaker is seeking to persuade, the receiver (i.e., the judge) is in a position that is clearly dominant to the attorney. Attorneys are then put in the somewhat tricky position of having to employ nonverbal behavior that connotes dominance (as dominant behaviors are more likely to persuade) yet, at the same time, display nonverbal cues to indicate both an awareness of and a respect for the judge's ultimate authority. Accordingly, this section will also propose ways in which attorneys can better navigate this seeming contradiction.

\section{A. Nonverbal Persuasive Tool \#1: An Attorney's Body}

As detailed in Part III, when it comes to the human body, speakers want to employ kinesic and physical appearance cues that maximize their perceived credibility and persuasiveness. ${ }^{168}$ The same, of course, is true of attorneys engaging in oral argument. Applying the social science behind these two nonverbal cues, what follows are some of the specific ways in which attorneys can both move and adorn their bodies during oral argument to enhance their ability to persuade a judicial audience.

\section{Eye Contact During Oral Argument}

First, one of the most effective ways an attorney can manipulate his body during oral argument is by employing eye contact with the judge. As one legal commentator has noted, "[t]he eye is the window of the mind, and the speaker does not live who can long hold the attention of any audience without looking it in the face." 169 Indeed, textbooks that deal with the subject of oral argument routinely counsel on the importance of eye contact. For example, in one textbook the authors advise:

Maintaining eye contact is a crucial element of persuasion. A listener's natural sensors pick up unspoken belief only if they see the eyes of the speaker. Looking at the judges communicates much more than words alone. In addition, eye contact heightens interest. If you move your eyes from one listener to another, you will draw all of the judges to your presentation.

\footnotetext{
168. See supra note 50 and accompanying text.

169. John W. Davis, The Argument of an Appeal, 26 A.B.A. J. 895, 898 (1940).

170. FONTHAM ET AL., supra note 14, at 217; see also CLARY ET AL., supra note 29, at 115 ("The importance of maintaining eye contact with each individual judge cannot be overstated.").
} 
Beyond those practical concerns, social science reveals that eye contact is also important for the role it plays in nonverbal persuasion. Specifically, as previously discussed, eye contact enhances both a speaker's perceived attractiveness and dominance, both of which, in turn, enhance a speaker's perceived persuasiveness. ${ }^{171}$ Of course, eye contact, like all nonverbal cues, does have an optimal level and, thus, advocates must avoid prolonged eye contact that rises to the level of staring. ${ }^{172}$ As the above quote indicates, attorneys appearing before a multi-judge panel can avoid this potential problem by simply looking at each judge in turn. For the attorney appearing before a single judge, however, he would be well advised not to maintain eye contact for more than seventy percent of the time (the percentage recommended by body language experts). ${ }^{173}$

Finally, attorneys should keep in mind that eye contact can be particularly meaningful when responding to a judge's question. As one text notes, "[s]ome advocates have the habit of always glancing downward each time a judge asks a question. It is as if the advocate is in search of the answer before the question is asked, a mannerism unlikely to conjure images of confidence." $" 174$

\section{An Advocate's Posture}

Second, as noted earlier, a person's posture carries quite a bit of communicative potential. Accordingly, given that the attorney is expected to stand during oral argument, ${ }^{175}$ oral advocates are routinely advised of the need to maintain excellent posture:

Plant your feet squarely on the floor and stand in one position; do not move around and do not rock or shift your weight from one leg to the other. Do not stray from the microphone. Do not lean on the podium. Stand straight and keep your hands free for relaxed, natural gestures. ${ }^{176}$

171. See supra notes 50-55 and accompanying text.

172. See supra notes $56-60$ and accompanying text.

173. See supra note 63 and accompanying text.

174. Carole C. Berry, Effective Appellate Advocacy: Brief Writing and Oral ARGUMENT 192 (3d ed. 2003).

175. See, e.g., JoHNS, supra note 28 , at 190 ("When you are addressing the court, remember to stand up, look up, and speak up. Proper courtroom etiquette requires that you stand when you address the court.").

176. ClARY ET AL., supra note 29, at 116; see also FONTHAM ET AL., supra note 14, at 218 ("Do not lean on the podium, stand cross-legged, or rock back and forth. These mannerisms tend to distract the judges."); Michael D. Murray \& Christy Hallam DeSanctis, Appellate ADVOCACY AND MOOT COURT 167 (2006) ("Do not sway back and forth or from side to side at the podium. You will make the panel seasick.... Do not grip the podium like a dying man or lean your 
As the last line of this quote suggests, while good posture is important, an attorney also wants to demonstrate some level of relaxation during oral argument. Indeed, as noted earlier, speakers who appear relaxed tend to appear more dominant and, thus, more persuasive. ${ }^{177}$ Accordingly, attorneys should be careful to exhibit good posture and, thus, avoid any temptation to sway or lean on the podium. At the same time, however, studies of nonverbal persuasion make clear that the attorney must refrain from adopting an overly rigid posture; doing so may connote nervousness and/or submission, which can undermine an oral advocate's ability to persuade. ${ }^{178}$ As one text on oral argument points out, "[f]requently the touch of nervousness manifests itself in bad habits that the attorneys themselves fail to notice, but that can be quite distracting to the court and that can detract from the effectiveness of an otherwise eloquent presentation."

\section{Gestures \& Overall Expressivity During Oral Argument}

Posture is not the only way in which a speaker's nervousness can betray him. Another common culprit is fidgeting. As noted earlier, gesturing can actually enhance a speaker's persuasiveness, but only when those gestures are in harmony with the verbal message. ${ }^{180}$ In contrast, gestures out of sync with the speaker's verbal message are likely to be perceived as signs of nervousness, which diminish the speaker's effectiveness. ${ }^{181}$ As one text on oral argument points out, "[h]and movements can be successfully used to drive home a point, but the advocate must be wary of repetitious movements that do not add meaning to the argument."

Furthermore, social science indicates that more expressive faces and gestures tend to make speakers more persuasive. In the context of oral argument, however, the formality of the setting may dictate a lower threshold of the appropriate level of expressivity. As David C. Frederick notes, "[i]n most judicial forums, the more animated a speaker becomes, the more foolish he tends to look." 183 Thus, advocates are generally advised to use gestures but in a more restrained way:

\footnotetext{
full weight on it or slouch with your elbows on it as if you are exhausted or lazy.").

177. See supra note 55 and accompanying text.

178. See supra notes 79-87 and accompanying text.

179. ClARY ET AL., supra note 29, at 116.

180. See supra notes $97-105$ and accompanying text.

181. See supra note 99 and accompanying text.

182. BERRY, supra note 174, at 191.

183. FREDERICK, supra note 14, at 187.
} 
Keep your gestures restrained: no pointing at the court or counsel, no pounding on the podium, no rocking on your heels, no fidgeting with your hair, no waiving about a pen, no jingling your car keys, no shuffling papers. Small hand gestures can be effective, such as showing the "broad" scope of argument or "weighing" alternatives.

Furthermore, in terms of an appropriate limit to how expressive gestures should be, one text suggests that "[a]ny arm gesture that puts your hands above the level of your shoulders is suspect. Think friendly counselor, not fire-and-brimstone preacher." "185

The question then becomes, what kinds of gestures are effective for the oral advocate? The simplest advice would be to use relatively constrained gestures that complement the verbal stream. More specifically, attorneys, like the politicians discussed earlier, ${ }^{186}$ could likely benefit from hand gestures that have been shown to have a persuasive impact. For example, such gestures would include those that involve steepling or a palms-down orientation. ${ }^{187}$

Of course, any gesture, no matter how persuasive it might be in isolation, can lose its effectiveness if it is overdone. As one text points out, "[n]atural hand gestures can complement your oral presentation, but you risk distracting the panel if these mannerisms are excessive." 188

\section{An Advocate's Dress}

In addition to kinesic cues, attorneys would also be wise to manipulate their physical appearance to enhance their perceived persuasiveness. Although attorneys, like all humans, are limited in those physical qualities over which they have control, attorneys can definitely manipulate dress. As discussed earlier, high-status dress is considered more dominant and, as a result, enhances credibility, perceived intelligence, and overall persuasiveness. ${ }^{189}$ As a result, attorneys are advised to dress appropriately:

Successful public speakers know that their dress must be appropriate to the occasion. The attire must indicate an awareness of the importance of the event. It should be neither bizarre nor offensive. It must be

\footnotetext{
184. JOHNS, supra note 28, at 190.

185. MuRRAY \& DESANCTIS, supra note 176, at 167.

186. See supra notes $106-14$ and accompanying text.

187. See supra notes $106-14$ and accompanying text.

188. UCla Moot Court Honors Program, Handbook of Appellate Advocacy 37 (Lawrence Brennan et al. eds., 3d ed. 1993).

189. See supra notes $164-67$ and accompanying text.
} 
remembered that the process of evaluation may commence even before a single word is uttered, and, therefore, counsel should be well groomed and appropriately dressed. ${ }^{190}$

In the legal setting, this high-status dress generally entails wearing a clean, attractive suit. ${ }^{191}$ Indeed, "[a] lawyer's attire can convey many messages: authority, confidence, affluence, conformity[,] or individuality." "192 Specifically, professional attire expert Mark O. Gill advises that "women should build on the classic five-piece suit of a blazer, knee-length jacket, skirt, pants[,] and shift dress. Men should build on classic suits, dress trousers[,] and sport jackets."193 Finally, attorneys should also be mindful that speakers with short hair, regardless of gender, are generally perceived as more credible. ${ }^{194}$

In terms of overall appearance (including hair, dress, and personal adornments) during oral argument, one text offers the following advice:

In every oral argument, whether it be in a real appellate court or in moot court, your appearance must be professional and appropriate. Wear your best job interview suit for an interview at a stodgy law firm. Wear your hair in a conservative lawyerly way. Jewelry and accessories (men's ties, women's scarves, chains, and earrings) should be somewhat subdued and preferably conservative. Do not wear a watch or jewelry that is loose and clunky that you might bang the podium with in the middle of your argument.

Finally, as one commentator dryly notes, "you will not be stopped from arguing if you wear a race-track suit or sport a rainbow necktie. You will just create the first impression that you have strayed in at the wrong bar." 196

\section{B. Nonverbal Persuasive Tool \#2: An Attorney's Voice}

Beyond kinesics and physical appearance, attorneys should also pay careful attention to how they speak during oral argument. As Part III.B

190. EdWARD D. RE \& JOSEPH R. RE, BRIEF Writing \& ORAL ARGUMENT 153 (8th ed. 1999).

191. See Jill Schachner Chanen, What Not to Wear: There's an Easy Fix for Even the Worst Fashion Faux Pas, 91 A.B.A. J. 52, 52 (2005).

192. Paul Reidinger, Dressing Like a Lawyer: Whether in a Law Office or Courtroom, What You Wear May be Almost as Important as What You Say, 82 A.B.A. J. 78, 78 (1996).

193. Chanen, supra note 191, at 52.

194. See supra notes 159-61 and accompanying text.

195. MURRAY \& DESANCTIS, supra note 176, at 166-67.

196. JoHNS, supra note 28, at 189 (quoting Robert H. Jackson, Advocacy Before the Supreme Court: Suggestions for Effective Case Presentations, 37 A.B.A. J. 801, 861 (1951)). 
explained, speakers are perceived as more persuasive when they speak at a more moderate rate, with minimal pauses and hesitations, with varied pitch, and with moderate loudness. ${ }^{197}$ When these qualities are absent, listeners are more likely to perceive the speaker as nervous and uncertain, which undermines perceptions of attractiveness and dominance. ${ }^{198}$ With those basic considerations in mind, the remainder of this subsection will discuss specific ways an attorney might manipulate his voice during oral argument for optimal persuasive impact.

\section{Rate of Speaking During Oral Argument}

As noted earlier, social science has revealed that a moderate speaking rate is generally gauged as being more persuasive. ${ }^{199}$ This information would seemingly be at odds with the advice typically given to oral advocates, which is to slow down the delivery. Indeed, as one text advises: "High speed is your enemy. It is hard enough to be understood when explaining something orally[-]speeding up just a little can lose your audience a lot." 200

Social scientists have cautioned, however, that when it comes to rate of speaking, there is an upper limit for persuasion. ${ }^{201}$ In other words, a speaker can only speak so quickly before he starts to undermine his effectiveness. Thus, an advocate should speak at a moderate rate but not so quickly that he cannot be easily understood. Social science also notes that one of the instances in which a slower delivery is preferred is when a speaker is explaining a more difficult or more crucial concept. ${ }^{202}$ As advocates may frequently be called on to explain a more complicated argument or facet of the law, they would be mindful to perhaps engage a slower rate of speech when so doing. As one text points out, "[a]lthough perhaps counterintuitive, it is enormously effective to pause and slightly lower your volume and slow your speed when you want the court to pay particular attention.",203

\footnotetext{
197. See supra Part III.B.

198. Id.

199. See supra notes 124-27 and accompanying text.

200. MURRAY \& DESANCTIS, supra note 176, at 167; see also ClARY ET AL., supra note 29, at 115 ("[S]peak with a slow enough cadence to be understood easily ....").

201. See supra notes $130-31$ and accompanying text.

202. See supra notes $128-29$ and accompanying text.

203. ClaRY ET AL., supra note 29, at 115.
} 


\section{An Advocate's Use of Pauses}

As the last quote in the preceding section indicates, attorneys may sometimes pause when speaking to make a particular point more effectively. Such advice is not uncommon: "The pause provides another effective change of pace. At the beginning of the argument, it gets the court's attention. Similarly, a pause in the midst of the argument will regain attention."204 However, as the previous discussion on paralinguistics makes clear, an attorney should use such pauses sparingly. Indeed, speech marked with excessive pauses is seen as less confident and, thus, less persuasive.

Furthermore, for the same reasons an attorney should limit pausing at all, an attorney should also be mindful that, if he should need to pause, he need not punctuate the pause by filling it with meaningless utterances. As one text writer notes:

Above all, try to consciously eliminate verbal fillers such as "uhhh," "ahhh," "ummm," and lackluster vernacular phrases such as "uh-huh," "ya-know," "like" (as in "It's like so illegal," or "The Constitution like bans this conduct."). These phrases are distracting and can make a judge tune you out. Worse yet, the judge might start a score card with how many "uhhh's" and "ummm's" you say in the argument; take it from us - that judge is not paying proper attention to the substance of your argument any more. ${ }^{20}$

Furthermore, as noted earlier, paralinguistic studies show that people whose speech is punctuated with these filled pauses are rated as less credible, less social, and even less attractive. ${ }^{206}$

\section{Pitch/Tone During Oral Argument}

The consensus among paralinguistic studies on pitch is that speakers who vary their pitch are perceived more positively. ${ }^{207}$ Thus, attorneys would be well advised to moderate their tone during oral argument. Of course, even without knowing the social science behind it, such advice is somewhat intuitive. For example, one text offers the following advice:

204. FONTHAM ET AL., supra note 14, at 218; see also RE \& RE, supra note 190, at 153 ("The advocate should accentuate key words and phrases and pause before and after a climactic sentence.").

205. MURRAY \& DESANCTIS, supra note 176 , at 168.

206. See supra notes 132-34 and accompanying text.

207. See supra note 140 and accompanying text. 
A monotone is boring. Modulate your voice. A particularly effective technique is to allow your voice to rise as the argument builds to a point, and drop it sharply for the climax. As you state your conclusion in a voice seemingly just above a whisper, your listeners will lean forward to hear it, showing that you are in control. ${ }^{208}$

Regardless of whether an advocate is comfortable manipulating his voice to the extent suggested in the previous quote, it is nonetheless important that the advocate vary his voice somewhat. This is not only because of the relationship between pitch and nonverbal persuasion, but because oral argument, when done correctly, should play out as a conversation between the judge and the attorney. When the attorney, however, is speaking in a monotone voice, either through nervousness or because the attorney is reading his argument, ${ }^{209}$ it becomes increasingly difficult for a conversation to actually take place.

\section{An Advocate's Volume}

Finally, one of the ways in which a speaker can persuade is by modulating the volume of his speech. As noted earlier, speakers who speak at a moderately high volume tend to be perceived as more persuasive. $^{210}$ For the oral advocate, then, a louder voice is typically more effective. As one text puts it, "[d]o not yell, but your voice should be louder than that required for the judges to hear. A commanding voice allows you to project a 'presence.' In addition, it suggests that you are in control, confident, and committed to your argument." ${ }^{211}$ Conversely, a voice that is too soft can be fatal:

One of the first tenets of either an oral argument, a speech[,] or a conversation is that the oralist must be heard.... The tendency to be timid afflicts many advocates who appear before an appellate panel. This must not occur, because a counsel, who cowers and is unable to be heard, undermines the argument from the beginning. Some judges simply will not strain to listen but rather choose to ignore what the advocate tries to say. ${ }^{212}$

208. FONTHAM ET AL., supra note 14, at 217.

209. See BERRY, supra note 174, at 190 ("Closely related to the monotone is the reading voice, because by definition, reading is a monological form of speech.").

210. See supra note 141 and accompanying text.

211. FONTHAM ET AL., supra note 14, at 217; see also JOHNS, supra note 28, at 190 ("Speak with authority. A timid, squeaky delivery seems tentative and weak; a strong voice projects confidence and commitment.").

212. BERRY, supra note 174, at 189. 
As with other nonverbal cues, ${ }^{213}$ however, there is likely an upper limit on what constitutes an acceptable volume, after which a speaker is no longer benefiting his cause, but may actually be hurting his argument. In selecting the appropriate volume, the oral advocate would be wise to consider the location of his argument and, specifically, his distance from the judge. ${ }^{214}$ After all, although the advocate does want to be somewhat loud, he does not want to be so loud that his presentation loses its conversational tone. As David C. Frederick points out, "[c]ounsel's first instinct arguing in a large courtroom might be to speak in a big voice to fill up the room. That is not necessary. The best advocates maintain a low-key, conversational tone with the court."

\section{Respecting the Judge's Dominance}

So far, Part IV has advised attorneys to incorporate nonverbal techniques that will help enhance their perceived dominance so as to facilitate persuasion. What makes the oral argument setting somewhat unique, however, is the fact that the attorney's primary audience is someone who is not only dominant to the speaker but is someone who expects attorneys to recognize and respect that dominance. Thus, if an attorney were to project too much dominance when appearing before a judge, that attorney may actually be undermining his ability to persuade. Indeed, as one commentator has pointed out, "individuals seeking to dominate others are more favorably impressed by actors who behave in a complementary, appeasing manner." 16 On the flip side, an attorney should not appear too submissive as that too can undermine his ability to persuade. As one text makes clear, "[c]ounsel should not be unduly humble .... A lawyer at argument is a professional doing an important job requiring intelligence and skill, not a peasant pleading for indulgence from the emperor."217

213. See, e.g., supra notes 130-31 and accompanying text.

214. See, e.g., Ruggero J. Aldisert, Winning on Appeal: Better Briefs and Oral ARGUMENT 355 (2d ed. 2003) ("If the lectern is fairly close to the bench, it is well to keep your voice on the same level and in the same tone that you would use in a conversation at a dinner table with one sitting across from you.").

215. FREDERICK, supra note 14 , at 187.

216. Keating, supra note 68, at 327; see also Larissa Z. Tiedens \& Alison R. Fragale, Power Moves: Complementarity in Dominant and Submissive Nonverbal Behavior, 84 J. PERSONALITY \& SOC. PSYCHOL. 558 (2003).

217. Ursula Bentele \& Eve Cary, Appellate Advocacy Principles and Practice 510 (4th ed. 2004); see also UCLA MoOT COURT HONORS PROGRAM, supra note 188, at 36 ("Try to be at once assertive yet deferential, but guard against sliding too far to either extreme. Being either too obsequious or too aggressive may alienate the court and cause it to lose respect for you."). 
In figuring out how to navigate this territory, attorneys should keep in mind the different roles of the attorney and the judge. Specifically, the attorney's role is to present his client's case and advocate on that client's behalf. It is within this realm that an attorney should be able to safely project dominance. As one text explains, "[c]ounsel is there to represent a client who has every right to have the court hear its case. The court's job is to decide it. Judges will not respect an advocate who is too submissive." 218 In other words, an attorney should project dominance over his case-in-chief when given permission to present the substance of his presentation: the facts, the cases, and the arguments.

Indeed, the attorney needs permission given that it is the judge's role to control the way in which oral argument unfolds. As a result, an attorney's nonverbals should acknowledge this understanding of the judge's role. $^{219}$ It is for this reason that attorneys generally understand they must cease talking when interrupted by a judge, that they must ask for additional time should time run out, and that the judge can even limit what the attorney is free to talk about during the oral argument. As Frederick advises:

Although many courts police time restrictions with a relaxed attitude, it is nonetheless a good practice to ask for permission before proceeding after time has expired. Doing so shows poise and respect for the court, which is typically reciprocated by the court granting permission to continue for a brief time. ${ }^{220}$

Such advice is in accord with social science, which reveals that one of the ways individuals communicate dominance vis-à-vis another is by controlling the conversation with that person. ${ }^{221}$

It is also important to know that social science has revealed, through what is known as the "visual dominance ratio," that individuals are expected to make more eye contact when listening to someone who is

218. FREDERICK, supra note 14, at 189.

219. Even the judge's position in the courtroom is intended to convey to everyone that it is the judge who is the most dominant. Not only is the judge centered in the room with all chairs facing him, but the judge also typically sits on a raised platform. See BURGOON ET AL., THE UnSPOKEN DiALOGUE, supra note 17, at 308-09 (discussing the role that central position and height play in communicating dominance).

220. FREDERICK, supra note 14 , at 200.

221. See generally John M. Wiemann, Power, Status and Dominance: Interpersonal Control and Regulation in Conversation, in SEQUENCE AND PATTERN IN COMMUNICATIVE BEHAVIOUR, supra note 15, at 85, 97 ("[I]nterruption becomes a tactic available for interactants to use to accomplish some conversational or relational goal-e.g.[,] to dominate a conversation [or] to establish dominance in a relationship ...."). 
dominant. $^{222}$ Thus, "[a]n advocate who avoids making eye contact... behaves rudely, because a judge will expect to be treated respectfully and speaking to someone without making eye contact is impolite....,223 For this reason, attorneys should generally look at judges while listening to them, yet not be surprised when the judge fails to look at the attorney when the attorney is speaking. ${ }^{224}$

The attorney who successfully navigates the somewhat thin line between dominance and submission will in essence be communicating nonverbally: "Your honor, I understand and recognize your dominance over these proceedings; however, when you give me leave to do so, I will in turn show you how dominant I am as to the case I am presenting and the arguments I am making." To understand, consider the following analogy:

Think of [oral argument] as a discussion between a first-year lawyer and the senior partner. Both bring a perspective to an issue and both attempt, through discussion, to come to some resolution of that issue. A satisfactory resolution cannot be achieved if the young lawyer is so fearful of the senior partner that he or she does not speak up when asked a question. A resolution also cannot be realized if one party is flippant, irascible, or condescending. ${ }^{22}$

In other words, the oral advocate should adopt nonverbal cues that better enable him to achieve what others have succinctly described as "an attitude of respectful intellectual equality."226

\section{CONCLUSION}

Social scientists have proven that, when it comes to a speaker's ability to persuade, the speaker's words are only a part of the equation. Indeed, a strong message coupled with strong nonverbal cues can result in greater effectiveness as an advocate. ${ }^{227}$ Accordingly, it is essential for oral advocates to not only understand the basic principles of nonverbal

222. See generally John F. Dovidio \& Steve L. Ellyson, Decoding Visual Dominance: Attributions of Power Based on Relative Percentages of Looking While Speaking and Looking While Listening, 45 SOC. PSYCHOL. Q. 106, 110 (1982) ("Higher power scores were associated with higher visual dominance ratios.").

223. FREDERICK, supra note 14 , at 186.

224. As Burgoon et al. explain, "increasing the amount of gaze during speaking is perceived as dominant, while increasing it during the listening phase is perceived as submissive." BURGOON ET AL., THE UnSPOKEN Dialogue, supra note 17, at 313.

225. BERRY, supra note 174, at 161.

226. JoHNS, supra note 28 , at 189.

227. See supra note 17 and accompanying text. 
persuasion, but also to understand how to utilize those principles when appearing before a judge. As outlined in this Article, a survey of social science studies in the area of nonverbal persuasion reveals a number of nonverbal techniques that attorneys can employ-using their bodies, their voices, and even their physical appearance - to maximize the attorney's perceived attractiveness and dominance, yet, at the same time, respecting the dominant position of the judge. In so doing, the attorney can become a more complete oral advocate, using not only his brain, but his entire body. 